\title{
ENTRE OLHARES: RELAÇÕES ENTRE LITERATURA E CINEMA
}

\begin{abstract}
Apenas alterei o rumo do olhar; antes, fixava um olho num fragmento do mundo exterior e acionava um botão. Agora é o olhar da reflexão que me interessa.

Milton Hatoum ${ }^{2}$
\end{abstract}

RESUMO: 0 presente artigo propõe uma reflexão acerca das aproximações entre literatura e cinema em nossa contemporaneidade, tendo como corpus de análise o filme 0 Labirinto do Fauno (2006), de Guillermo Del Toro. Primeiramente, procuraremos definir a relação existente entre a arte literária e a cinematográfica na obra. Em seguida, aprofundaremos a leitura observando as especificidades de cada forma narrativa lliterária e cinematográfical e seu entrelaçamento, tendo como fio condutor de nossa análise o foco narrativo que constitui a obra. A escolha do elemento da narratividade e da construção do ponto de vista em nosso estudo deve-se ao fato de que a tematização do "olhar", a nosso ver, constitui não apenas o próprio princípio de narração do filme e o diálogo entre literatura e cinema proposto pela obra, como, de maneira simbólica, representa a complexa discussão das relações entre essas artes em nossa sociedade atual.

1 Mestre na área de Estudos Comparados de Literaturas de Língua Portuguesa pela faculdade de Letras da FFLCH-USP. Integrante do grupo de pesquisa Produções Literárias para Crianças e Jovens (CNPq) em Estudos Comparados de Literaturas de Língua Portuguesa pela faculdade de Letras da FFLCH-USP. Professora de Língua Portuguesa e Literatura na rede particular de ensino.

2

HATOUM, 2004. 
PALAVRAS-CHAVE: literatura; cinema; leitura; foco narrativo; olhar.

ABSTRACT: This paper proposes a reflection on the similarities between literature and cinema in our contemporary world, with the corpus analysis the film Pan's Labyrinth (2006), Guillermo Del Toro. First, try to define the relationship between literary art and film art in the work. Then delve reading observing the specificities of each narrative form (literary and cinematic) and its relationship, with the thread of the narrative focus our analysis that constitutes the work. The choice of the element and the construction of narrative point of view in our study is due to the fact that the thematization of the "look", in our view, is not only the very principle of film's narration and dialogue between literature and cinema proposed for the work, as, symbolically, represents the complex discussion of the relationship between these arts in our society today.

KEYWORDS: literature; cinema; reading; narrativefocus; look. 


\section{Caminhos e percalços}

Poucas não são as dificuldades com as quais nos deparamos diante da proposta de refletir sobre as relações estabelecidas entre a arte literária e a cinematográfica. Ainda que seja nítida a aproximação entre as duas artes em nossa contemporaneidade, ou explícita nos casos em que há a intenção de "adaptar" uma obra literária ao cinema, a discussão segue diferentes caminhos, os quais perpassam linhas teóricas e investigativas variadas. Dessa forma, as relações entre literatura e cinema são analisadas sob a luz não apenas das teorias literária e cinematográfica, quanto pelo olhar da Semiótica, da Literatura Comparada, da Psicologia, da Sociologia, da História da Arte, dentre outras. A multiplicidade de perspectivas que direcionam o entendimento dessa relação é consequência de uma série de elementos históricos, sociais, culturais, políticos e econômicos que entram em jogo e que extrapolam as questões puramente estéticas e técnicas de cada arte em seu processo de representação da realidade (BELLO, 2005, p.144).

É imprescindível ressaltar que, além das dificuldades encontradas com respeito à diversidade de elementos envolvidos em tal aproximação, muitos estudos propõem-se a analisá-la partindo de uma perspectiva comparativista tradicional em que se buscam fontes e influências, em especial aqueles que visam analisar o processo de adaptação cinematográfica de obras literárias com o intuito de comprovar a "fidelidade" com relação à obra primeira. Atitudes estas culminam na supervalorização uma arte em relação à outra e geram mesmo um "regime de disputa, que vai suscitando uma série de divergências entre a literatura e o cinema" (SOUSA, 2001, p. 27). A busca incansável de "influências" e a consequente corrida para provar qual arte seria superior encerram um trabalho estéril, uma vez que entre a literatura e o cinema estabeleceu-se, progressivamente ao longo das épocas, um "conjunto de relações sob a forma de um circuito de mão dupla" (GUIMARÃES, 1997, p.109).

Seria extremamente redutora, e em nada crítica, nesse sentido, uma leitura das relações entre a arte literária e a cinematográfica com base apenas em nosso campo específico de estudo, ou seja, dos estudos literários, não 
levando em conta tanto as diferenças de cada procedimento artístico e das linguagens que utilizam, como as posições mais recentes que "consideram as transposições semióticas como atividades exercidas por receptores inapagáveis do estrato da socioesfera cultural a que pertencem" (SOUSA, 2001, p. 27).

Nessa ordem de ideias, o estudo que se direcione a observar e compreender as relações entre literatura e cinema e que ultrapasse a atitude comparativista de observar semelhanças e diferenças entre as artes, requer um "olhar" amplo sendo fundamental articular a investigação com elementos sociais, políticos, culturais, em suma, com a História em um sentido abrangente, levando em consideração o produtor da obra fílmica como um leitor provido de "reações afectivo-volitivas, de expectativas, "pré-juízos' ou 'pré-conceitos' [...] e de uma contextualidade histórico-temporal" (SOUSA, 2001, p.33), características que participam do estabelecimento do diálogo interartes.

A investigação deve ainda procurar compreender as operações de interinfluências que uma linguagem pode exercer sobre a outra, bem como a maneira como se processam as traduções intersemióticas promovidas nessa relação, construindo "uma indagação que formule a relação entre os textos e as interprete", observando "como, repetindo-o, o segundo texto "inventa' o primeiro" (CARVALHAL, 2006, p.57-58), redescobrindo-o, dando-lhe outros significados, resultando no trabalho de construção poética de absorção e transformação.

Diante da amplitude da questão, nossa proposta será tecer reflexões acerca das aproximações entre literatura e cinema, tendo como corpus de análise o filme 0 Labirinto do Fauno (2006), de Guillermo Del Toro. Inicialmente, procuraremos definir a relação existente entre a arte literária e a arte cinematográfica na obra, já que não há uma única obra literária fonte que sofre a adaptação para a produção do filme. Em seguida, aprofundaremos a leitura observando as especificidades de cada forma narrativa lliterária e cinematográfical e o entrelaçamento dessas duas formas de expressão na transposição intersemiótica, tendo como fio condutor de nossa análise o 
foco narrativo que constitui a obra. A escolha do elemento da narratividade e da construção do ponto de vista como direcionamento de nosso estudo deve-se ao fato de que a tematização do "olhar" e sua relatividade, a nosso ver, constitui não apenas o próprio princípio de narração do filme e o diálogo entre literatura e cinema proposto pela obra, como também, de maneira simbólica, representa a complexa discussão das relações entre essas artes em nossa sociedade atual.

\section{Um labirinto de olhares em caminhos que se bifurcam}

Em 0 Labirinto do Fauno, somos transportados para a Espanha de 1944, após o final da Guerra Civil Espanhola (1936-1939) e a consolidação do regime nacionalista do general Franco. 0 filme apresenta-nos a história de Ofélia, uma garota delicada e sonhadora de 13 anos, que viaja com a mãe, Carmen, a qual sofre uma gravidez de risco, para um pequeno posto militar ao norte do país. Chegando ao local, a menina encontra Vidal, um cruel capitão do exército franquista, novo marido de Carmen e que não sente nenhum afeto pela enteada. Enquanto Vidal se preocupa em acabar com a resistência republicana, Mercedes, empregada do capitão, ajuda, clandestinamente, 0 grupo de rebeldes, cujo líder é seu irmão, com apoio do médico local.

Em uma noite, Ofélia explora os arredores do lugar e encontra as ruínas de um velho labirinto, no centro do qual reside um fauno, que a reconhece como uma princesa, última de sua estirpe, herdeira do trono do Reino Subterrâneo. 0 misterioso ser desafia a menina a realizar três perigosas provas antes da lua cheia que, se cumpridas, comprovarão sua identidade. No desenrolar dessa missão, Ofélia desloca-se constantemente entre o mundo "real" e o mundo maravilhoso, vivendo aventuras próprias de um conto de fadas.

Podemos perceber, portanto, a composição da obra por duas narrativas, cada uma delas representando um mundo ou uma realidade distinta. Com uma clara intenção realista e tendo como base os fatos históricos, a primeira narrativa representa o mundo "real" do franquismo autoritário e 
repressor que, assumindo um discurso que se pretende monológico, almeja a homogeneidade e submissão de todos que estão sob sua liderança, tentando, incansavelmente, sufocar as ações dos rebeldes, cuja palavra de ordem seria a negação do sistema. Ademais de uma luta armada, temos uma luta ideológica pela repressão intelectual dos indivíduos e imposição de uma "verdade" absoluta construída pelo sistema dominante e incorporada pela ditadura (ORWELL, 2006, p. 276). Ao passo que a segunda representa o mundo da fantasia retomando a tradição e as convenções dos contos de fadas, na medida em que, em meio ao maravilhoso da magia feérica (reis, princesas, fadas, monstros e objetos mágicos), temos como problemática motriz a busca da heroína, a qual precisará, como um ritual iniciático, vencer obstáculos e provas para alcançar sua autorrealização existencial (COELHO, 1988, p. 14) e, ao mesmo tempo, tal viagem às margens da imaginação acaba se tornando a única saída para Ofélia no enfrentamento do mundo repressor e violento da ditadura, no qual se vê solitária.

Dessa maneira, no que concerne ao conto de fadas vivido por Ofélia, não há uma obra literária fonte que sofre uma adaptação, mas um conjunto de textos pertencentes já ao nosso imaginário e repertório cultural sendo revisitados e reinterpretados. 0 que nos parece fundamental é que a aproximação entre essas duas realidades concretiza-se no embate entre dois discursos entrelaçados pelo cinema, a saber, o discurso da historiografia e o discurso literário. Tal entrelaçamento nos aproxima das ideias de Sousa de que "o cinema pode justamente ser usado na elaboração de leituras possíveis do texto literário" (SOUSA, 2001, p. 35).

Levando em conta as especificidades de cada forma narrativa imbricada (literária e cinematográfica), cabe-nos observar quais recursos utilizados no filme servem para concretizar o processo narrativo, uma vez que o elemento da narratividade, em consonância com as considerações de Bello (2005), parece-nos ser aquele que relaciona de maneira mais íntima "romance lou novela ou contol e filme" e, consequentemente, "a exploração das diversas unidades narrativas dos dois tipos de texto aquela que revela um território mais rico de sugestões interpretativas, estruturais e estéticas" (BELLO, 2005, p.155). 
Analisando as cenas iniciais do filme, podemos observar vários procedimentos utilizados para contar/narrar a sequência de acontecimentos que se desenvolve diante dos olhos do espectador. Este se depara, primeiramente, com um breve texto: "Espanha, 1944./A guerra civil terminou./Escondidos nas montanhas, grupos guerrilheiros/ainda combatem o novo regime fascista, que luta para suprimi-los". Recorre-se, assim, à palavra escrita para situar o tempo (histórico) e o espaço (concreto) em que se passará a ação; as letras pequenas e brancas e o fundo negro proporcionam o tom sério e documental ao texto verbal, ao mesmo tempo em que os sons de ventania, de um sussurro agonizante e de uma melodia melancólica constituem uma atmosfera de medo e terror.

É iniciada, dessa forma, a construção da representação do mundo "real" da luta dos rebeldes contra o regime ditatorial e o espectador/leitor, sendo inserido em um ponto de vista próprio da historiografia em que se "pressupõe objetividade" (LEITE, 2001, p. 71), é motivado a ativar seus conhecimentos prévios sobre o momento que será retratado, certamente cenas de guerras, torturas, dentre outras, aparecem em sua mente.

Em seguida, as letras desaparecem, a tela escurece, o tom negro é substituído por um verde sombrio de pedras, o sussurro e a música intensificamse e a câmera desliza horizontalmente, até que a previsão do espectador concretiza-se: surge uma mão ensanguentada, que progride até a imagem vertical de uma menina deitada em seus últimos suspiros. 0 jogo de câmera continua e, no compasso da melodia e a partir da técnica do close- up, nosso olhar é levado a viajar por um giro em espiral em forma de labirinto até penetrar na escuridão e profundidade do olho da garota. Nesse exato momento, uma voz, masculina e grave, inicia o seguinte discurso:

Conta-se que há muito, muito tempo, no Reino Subterrâneo onde não existe mentira nem dor, vivia uma princesa que sonhava com o mundo dos humanos. Ela sonhava com o céu azul, a brisa suave e o sol brilhante. Um dia, burlando toda a vigilância, a princesa escapou. Uma vez do lado de fora, a luz do sol a cegou e apagou da sua memória qualquer indício do 
passado. Ela se esqueceu de quem era e de onde vinha. Seu corpo sofreu com o frio, a doença e a dor. E, passados alguns anos, ela morreu. No entanto, seu pai, o rei, sabia que a alma da princesa retornaria talvez em outro corpo, em outro tempo e em outro lugar...

0 verbal é utilizado novamente, mas agora em sua modalidade oral no tom do "era uma vez". De pronto reconhecemos o contador de histórias, descendente dos narradores primordiais, que contavam o que tinham ouvido ou conhecido, representando a memória dos tempos a ser preservada pela palavra e transmitida de geração para geração (COELHO, 2000, p. 109). Essa voz, que se faz ouvir nos contos de fadas, insere-nos na perspectiva de um mundo de fantasia, no qual prevalece o maravilhoso, em que tempo e espaço situam-se fora da realidade conhecida, noções que, de acordo com Coelho (2000, p. 104), resultam da consciência mítica, peculiar à humanidade no início dos tempos. Retoma-se, assim, um modo de narrar que considerava o mundo como um todo e conseguia representá-lo por um ponto de vista fixo (GOTLIB, 1988, p. 30).

É importante ressaltar que alguns recursos cinematográficos são utilizados para enriquecer o discurso desse narrador. Simultaneamente à narração oral, a câmera desloca-se horizontalmente em um cenário sombrio que seria o Reino Subterrâneo e, depois, ao longe, acompanhamos uma garotinha subindo longas escadas circulares, até que uma forte luz invade a tela; luz que cegou a princesa, mas que também desnorteia o olhar do espectador, até então acostumado com a escuridão das cenas anteriores. Portanto, enquanto a voz narra, a câmera não só descreve e mostra-nos as imagens, as quais com o recurso apenas da palavra ficariam a cargo da imaginação do ouvinte/leitor, mas também surpreende nossos sentidos perceptivos fazendo-nos experimentar brevemente a sensação da personagem.

Concretiza-se, simultaneamente, portanto, não só a experiência conceptual, própria da literatura, mas, principalmente, perceptual da técnica cinematográfica. A conjunção das técnicas narrativas na obra, ou seja, a mescla do discurso literário com a narração paralela por meio de imagens, aproxima-se 
das ideias de Walter Benjamin acerca do cinema, em que a reprodução técnica atingiu tal padrão de qualidade que esta arte "podia transformar em seus objetos a totalidade das obras tradicionais, submetendo-as a transformações profundas" (BENJAMIN, 1994, p. 167). Além disso, a procura de "equivalências" na tradução intersemiótica do verbal ao visual no filme, por parte do cineasta, acaba por efetuar "uma renovação e uma fecundação da produtividade dos signos e códigos técnico-narrativos da sétima arte" (SOUSA, 2001, p. 40), promovendo um processo criativo na relação interartes estabelecida nas cenas analisadas.

Na cena seguinte, vemos a mesma garota, agora sabemos que se chama Ofélia, em viagem com a mãe. Durante o percurso, ambas iniciam um diálogo, no qual a mãe critica a filha por gostar de ler contos de fadas. Tal diálogo é extremamente elucidativo como técnica narrativa, uma vez que, sem a mediação de um narrador, revela peculiaridades de Ofélia e da mãe, dando-nos indícios da mente propícia da menina a imaginar aventuras que ultrapassam a realidade objetiva, em oposição a Carmen, que vê como imaturidade o gosto da filha.

A viagem, porém, é interrompida pelo mal estar de Carmen. Caminhando pela floresta, Ofélia encontra uma pedra esculpida em forma de olho e a encaixa em uma velha estátua, de cuja boca sai um inseto. A garota pergunta ao inseto se ele é uma fada e tenta pegá-lo, nesse instante, a mãe chama Ofélia e a repreende por ter sujado os sapatos. Enquanto o espectador começa a pensar no absurdo da atitude da menina, o carro segue caminho e a câmera o focaliza pela perspectiva do inseto, ou seja, quem olha agora é o inseto. Ora, esse "olhar" imposto pela câmera faz o espectador duvidar da conclusão inicial: talvez a menina não estivesse errada, talvez houvesse outra realidade além da objetiva e concreta... Na cena descrita, utiliza-se um "plano-ponto-de-vista" (RAMOS, 2005, p. 251), isto é, um plano em que a câmera assume a posição de um sujeito de modo a nos mostrar o que ele está vendo. Assim, o "olho da câmera" impõe-nos a olhar o fato sob uma nova perspectiva, quebrando com a perspectiva única do indivíduo que vê, experiência inovadora proporcionada pelo cinema e que se constituiu como a "novidade histórica do cinema" (XAVIER, 1983, p. 84). 
Por meio da cena analisada acima, as ações seguem um curso linear, tanto no que se refere à tomada do posto militar pelos rebeldes, quanto às aventuras que serão vividas por Ofélia após a revelação de sua identidade de princesa pelo fauno. Entretanto, tal linearidade é fragmentada, pois o filme desloca-nos, constantemente, do mundo terrível da ditadura ao não menos tenebroso dos contos de fadas, intercalando cenas das duas histórias, que correrão paralelamente. 0 espectador é levado a acompanhar as histórias por uma estrutura labiríntica construída graças à técnica da montagem, a qual, segundo Eisenstein (1990), baseia-se na lógica da implicação, ou seja, na busca de um todo coerente, o leitor estabelece relações entre duas ou mais partes justapostas (EISENSTEIN, 1990, p. 14).

Se a estrutura da narrativa já é um desafio ao espectador, o qual, devido à constante mudança de perspectiva na intercalação das histórias, deverá ter atenção a cada detalhe, rapidez no olhar e na capacidade de estabelecer relações e inferências, além do constante jogo que o "olho" da câmera nos impõe; o que dizer do labirinto também de cada fragmento ou parte, que o obrigará a transitar entre linguagens e códigos que intentam representar cada mundo, e que, amalgamados e entrelaçados, vão dos objetos ao verbo, do som à imagem?

Experimentamos, então, sensações de medo e terror ao presenciar cenas de torturas e assassinatos praticados pelo sádico capitão Vidal, intercaladas a imagens de seu olhar frio, dos jogos de câmera que descrevem lentamente sua farda e botas impecáveis, seu caminhar em marcha. Somos também obrigados, pelo "olhar" da câmera, a observar detalhadamente a mecanicidade com que, ao som quase demoníaco de uma antiga vitrola, o vilão lidava com o próprio barbear e cuidava de seu relógio, objeto que nos insere num mundo racional e objetivo. 0 acúmulo crescente de cada fragmento de cena acaba por construir uma cadeia de representações que constitui a personagem do capitão como uma figura maligna em relação metonímica com a ordem repressora dominante. Vidal não seria só um comandante militar, mas o ponto de vista que assume diante do mundo que o cerca o faz encarnar a representação do próprio sistema, em que prevalece o medo e não há espaço para a liberdade, o sonho e a fantasia. 
Da mesma maneira, ainda com respeito a esse mundo "real", ações praticadas pela mãe de Ofélia como as insistentes críticas à imaginação fértil da filha, as imagens de suas roupas sem feminilidade e de seu olhar vazio e melancólico, bem como as repetidas vezes em que a câmera focaliza a cadeira de rodas, na qual é obrigada a sentar-se pela imposição do marido; provocam-nos sensações de estaticidade e falta de liberdade, o que poderia representar obediência e submissão à ordem dominante. Representações essas que se opõem à personagem de Mercedes, cujas ações de traição ao capitão e o olhar desconfiado nos trariam outra perspectiva dessa realidade, daqueles que a questionam e a enfrentam. Além disso, é pelo som que se faz presente esta personagem, é ela quem protege e acolhe Ofélia sussurrando uma canção de ninar, que constituirá a trilha sonora do filme, desde a cena inicial, e que provocará a atmosfera de tristeza e desesperança da obra, relacionando-se também com o universo infantil.

Outra observação importante é o fato de a obra opor-se à visão maniqueísta da realidade, isto é, relativiza a tradicional dicotomia entre bem e mal. 0 filme espanta e choca aquele espectador que, inocentemente, esperaria que o conto de fadas vivido por Ofélia fosse romantizado como acontece em grande parte das produções literárias e cinematográficas atuais, destinadas ao público infantil. Nestas, realça-se o caráter aventuresco das ações e peripécias, reduzindo o valor intrínseco dos contos de fadas, nos quais o mal é tão onipresente quanto a virtude (BETTELHEIN, 1980, p.15) e cujo significado primitivo estava intimamente relacionado com a "verdade" dos mitos e com um determinado saber fundamental do ser humano (COELHO, 1988, p. 15). Ao contrário, em 0 Labirinto do Fauno, somos conduzidos pelo olhar doce, inocente e, ao mesmo tempo, questionador de Ofélia, a duvidar, como a heroína, das palavras e atitudes do fauno, porta voz do mundo fantástico. A monstruosidade das formas desse ser e sua voz áspera, as sombras e o eco de sua morada, cuja entrada se dá pelo velho labirinto, bem como as constantes imagens noturnas da lua; constroem uma atmosfera de mistério e suspense, provocando sentimentos de medo e terror muito mais no espectador, que na própria Ofélia, fazendo com que o conto de fadas vivido pela menina seja tão tenebroso quanto a vida "real" da ditadura franquista. 


\section{Mito: reiteração e recriação}

De certa maneira, a aventura maravilhosa vivida por Ofélia, instaurada no contexto da ditadura espanhola, destaca-se consideravelmente, se temos como objetivo analisar a relação entre literatura e cinema na obra. Contudo, não podemos esquecer a figura fundamental do labirinto que não apenas está presente concretamente na película, como assume caráter central por constituir o título da obra, cuja referência ao antigo mito grego é nítida já que de "Labirinto do Minotauro", substitui-se apenas o elemento do monstro por "O Labirinto do Fauno". Além disso, o filme é contextualizado em um momento histórico, em certa medida, muito próximo ao mito original, ou seja, temos uma situação de opressão instaurada pela ditadura franquista, cujo líder Vidal, da mesma maneira que Minos de Creta, não medirá esforços e vidas para manter a soberania da ordem estabelecida.

Na medida em que há a retomada da imagem mitológica do labirinto, faz-se necessário debruçarmo-nos sobre questões intrínsecas ao gênero mito, a fim de compreendermos esse processo de revisitação que se instaura entre a antiga tradição e momentos posteriores do pensamento humano.

De origem remota e popular, os mitos constituem-se em narrativas que, por meio do pensamento maravilhoso, exemplificam a busca do ser humano que ao longo dos tempos procura entender o mundo que o cerca e a si mesmo. De maneira abrangente, o mito define-se por contar uma história sagrada, relatar um acontecimento originado em um tempo primordial. Como relatos próprios de um momento da "criação", tais histórias acabam por revelar modelos de ritos e de atividades significativas do ser humano, concedendo significado e valor à existência. Dessa maneira, a compreensão da estrutura e da função dos mitos nas sociedades tradicionais, de acordo com Mircea Eliade, não se refere apenas a "explicar uma etapa na história do pensamento humano, é também compreender melhor uma categoria de nossos contemporâneos" (ELIADE, 1963, p. 10).

Longe de ser uma mera fabulação, as narrativas míticas constituem-se em um elemento indispensável da civilização humana, ao qual se recorre constantemente. Sobrevivendo no imaginário coletivo da humanidade, entendendo-se 
imaginário como um reservatório coletivo de imagens, materializadas ou mentais, ou seja, um sistema organizador de imagens partilhadas por seres de uma mesma cultura (DURAND, 1995/ MELLO, 2007); os mitos e suas imagens reaparecem de tempos em tempos na criação artística e sofrem metamorfoses, necessárias à expressão dos conflitos do homem em cada momento histórico (CASSIRER, 1992). Assim, imagens e valores, pertencentes ao imaginário coletivo, vão sendo recuperados e relidos a cada época e, consequentemente, acabam por atualizar esse mesmo imaginário.

Seguindo os passos da heroína Ofélia, notamos que, logo ao chegar ao posto militar do capitão, a menina conhece as ruínas de um labirinto ao perseguir o voo de um estranho inseto. Da mesma maneira que a personagem, 0 espectador é conduzido, pelo "olhar" da câmera que intenta representar o ponto de vista de Ofélia, a penetrar por alguns instantes nas bifurcações do labirinto. Quando estamos completamente envolvidos nessa caminhada, a menina é interrompida e alertada por Mercedes, que define o labirinto como "Um monte de pedras velhas que sempre estiveram aí. Antes mesmo que o moinho. É melhor nem chegar perto, pode se perder."

Ora, ainda que o apresente de forma simples, a mulher nos dá indícios importantes sobre o lugar, pois não apenas temos de fato o labirinto em sua estrutura física, como um entrecruzamento de caminhos que nem sempre levam a uma saída, mas utiliza a palavra "sempre" para indicar o tempo de sua construção, vocábulo de forte conotação referente a uma origem remota, do tempo primordial e imensurável do mito. Além disso, a palavra "perder-se" apresenta forte ambiguidade se levarmos em conta, além do sentido de confundir-se ou desorientar-se, a própria relação simbólica do mito grego, do labirinto como os complexos caminhos do inconsciente humano (BRANDÃO, 2002, p. 161).

0 percurso inicial de Ofélia pelo labirinto ocorre na primeira noite de estada no posto militar. Com medo de dormir naquele lugar estranho e novo, atende ao pedido da mãe grávida e começa a contar uma história a seu irmão. 0 inseto das cenas iniciais, então, entra pela janela do quarto, aproxima-se de Ofélia e se transforma, assumindo a forma de uma fada. Esta chama para 
fora a menina que, maravilhada, segue o misterioso ser que a encaminha até o centro do labirinto. Lá dentro, a fada posiciona-se por segundos diante de uma estátua, cuja imagem representa metonimicamente o desfecho da aventura, mas a garota não percebe tal mensagem. Por fim, o Fauno apresenta-se a Ofélia e the propõe o desafio de cumprir três provas para comprovar sua verdadeira identidade de princesa.

A fada, além de encaminhar a menina pelas tortuosas proposições do labirinto, constitui-se como grande mediadora, a principal responsável por guiar Ofélia em direção a seu destino no desenrolar da aventura. Nesse sentido, algumas questões parecem-nos imprescindíveis no que se refere à retomada da imagem do labirinto: se o desafio proposto à heroína não é desvendar o labirinto, este seria um mero elemento decorativo da obra? Se sim, o título seria supérfluo e uma incoerência por parte do diretor?

Diante de tais questionamentos, somos obrigados a buscar em outros elementos do filme a resposta para nossa análise. Longe de ser um mero detalhe do cenário, podemos observar que, além de retomar o cenário de dominação tirânica das origens do mito, o diretor apropria-se da imagem do labirinto, como um espaço concreto de caminhos tortuosos de difícil acesso, ampliando-a para a constituição da arquitetura estética da obra.

Observando, atentamente, as técnicas cinematográficas mencionadas anteriormente para concretizar a narração do filme, notamos a construção de vários pontos de vista pelos quais o espectador é conduzido a observar os fatos. Ora acompanhamos dois pontos de vista próprios da historiografia, seja experimentando sensações de medo e terror ao presenciar cenas de torturas e assassinatos praticados pelo sádico capitão Vidal, seja compartilhando da perspectiva daqueles que questionam e enfrentam essa realidade, como os rebeldes, o médico e, em especial, Mercedes. Ora somos colocados na perspectiva de um mundo de fantasia do maravilhoso. Uma vez que as duas narrativas são intercaladas, o espectador é levado a acompanhar as histórias por uma estrutura labiríntica construída pela técnica da montagem. Além da construção da diversidade de perspectivas das personagens, salientamos a utilização do chamado "plano-ponto-de-vista" do cinema. Por 
essa técnica, às vezes, observamos os fatos pelo olhar de Ofélia, outras pelo do capitão ou mesmo da fada, representante do mundo maravilhoso. Assim, o "olho da câmera" impõe-nos a todo o momento olhar o fato sob uma nova perspectiva.

0 percurso do espectador pelo labirinto arquitetado esteticamente pela obra encerrar-se-á na cena final do filme. Fugindo do padrasto e sem saber em que consistiria a última tarefa, Ofélia leva o irmão recém-nascido ao fauno no centro do labirinto. 0 misterioso ser revela que a heroína deverá sacrificar o irmão a fim de que o portal se abra para a entrada ao Reino Subterrâneo, a menina, porém, recusa-se a fazê-lo e é repreendida pelo o fauno. Nesse momento, chega Vidal, e somos levados, pelo "olhar" da câmera, a observar a cena pela perspectiva do capitão, mas o que vemos é Ofélia falando sozinha.

Em meio essa ambiguidade, Vidal recupera o bebê, mata Ofélia e, em seguida, é assassinado pelos rebeldes, retornamos, assim, à cena de abertura do filme, chegamos ao ponto final do labirinto. Aos pés de Mercedes e ao som da ininterrupta canção de ninar, a menina agoniza e se vê no agora, iluminado Reino Subterrâneo, reencontra sua mãe e seu pai e, este lhe informa que ela cumpriu sua última missão: derramou o próprio sangue salvando um inocente, decisão moral e ética que acabou por comprovar sua identidade de princesa.

Ao final da história, percebemos que se constrói um labirinto de olhares em caminhos que se bifurcam, propondo desafios de modo a fazer o espectador/leitor percorrer um intrincado espaço textual com relação tanto à estrutura narrativa e à intertextualidade com a tradição literária, quanto às linguagens utilizadas na tessitura da obra. 0 leitor, ao iniciar a fruição do filme, inicia um verdadeiro jogo, em verdade, não é Ofélia, mas o próprio espectador que deverá desvendar o labirinto. 


\title{
Pelas veredas do olhar
}

Se Ofélia tem como guia a fada, resta-nos perguntar: há saída para o espectador? Este se perderia em meio à estrutura labiríntica da obra, restando-lhe apenas a sensação do insólito da história narrada? Parecem-nos extremamente esclarecedores os minutos finais do filme que apresentam, após a entrada de Ofélia finalmente ao Reino Subterrâneo, simultaneamente às imagens da floresta e de uma flor desabrochando, a voz do narrador primordial encerrando a obra com o seguinte discurso:

\begin{abstract}
Diz-se que a princesa voltou para o reino de seu pai e reinou com justiça e bondade por muitos séculos, que foi amada por seus súditos e que deixou detrás de si, poucos rastros de sua existência, visíveis somente para aqueles que saibam onde olhar...
\end{abstract}

Há, portanto, um "fio de Ariadne", um elemento que proporciona unidade e coerência ao que parecia fragmentado: o "olhar". A palavra "olhar" não só encerra a obra, como nos induz a fazer um retrospecto das várias imagens de "olho" presentes no filme: é pelo olho da menina, que entramos na história; é encaixando o olho na estátua, que a fada aparece e a aventura começa; é o olho do capitão que cruza os dois mundos etc. Ao chamar nossa atenção para o olhar, impõe-nos a participar ativamente do processo interpretativo e recapitular tudo o que foi visto e sentido. Somos obrigados a refletir sobre o olhar de Ofélia e do capitão e, principalmente, sobre o nosso olhar. Olhar astuto e inteligente, com atenção a cada detalhe, rapidez e capacidade de estabelecer relações e inferências, atitudes necessárias para resolver as proposições múltiplas para conhecer o espaço textual e, enfim, vencer o desafio labiríntico, chegando a um entendimento da obra.

De maneira ainda mais ampla, não podemos perder de vista que o filme, produzido em 2006, aproxima-se de uma linha da ficção cinematográfica de países que viveram os embates da ditadura militar pós Segunda Guerra 


\section{LITERARTES, n.2, 2013 - artigo - Joana Marques Ribeiro}

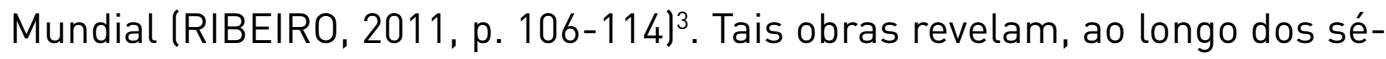
culos XX e XXI, o crescente interesse, não apenas em compreender os fatos históricos e colocar em questão os vários discursos que foram gerados acerca dos trágicos acontecimentos, bem como recontar e reconstruir a memória dos anos silenciados pela ditadura (SÁNCHEZ-BIOSCA, 2006).

Ao recontar a história do passado oferecendo-nos diversos olhares e pontos de vista pela técnica do cinema, seja da hegemonia dominante ou dos rebeldes, seja do maravilhoso mítico, a obra permite que ampliemos nosso olhar, não nos identificando totalmente com um único olhar, mas colocando em discussão todos eles e o nosso próprio, que, inevitavelmente, insere-se em nosso presente histórico com as leituras e vivências de seres sociais que somos. Aproximamonos, nesse sentido, às reflexões de Xavier (1988) sobre o fato de que o olhar que é "fabricado" pela técnica cinematográfica realiza um processo que envolve "a ação de um olhar que, ao invés de estar voltado para mim, olha por mim, me oferece pontos de vista, coloca-se entre eu e o mundo" (XAVIER, 1988, p. 382).

Observamos, ainda, de que maneira a reiteração e recriação do mito do labirinto em 0 Labirinto do Fauno propõe a reflexão sobre o momento histórico retratado no filme e novos olhares sobre nosso presente, reafirmando a função mítica original como expressão significativa da permanente busca do ser humano de conhecimento sobre a vida.

Podemos afirmar, por fim, que o tema do "olhar" e sua relatividade na obra analisada constitui, não apenas o próprio princípio da narração do filme e, essencialmente, o diálogo entre literatura e cinema proposto pela obra, como também, de maneira simbólica, representa a complexa discussão das relações entre essas artes em nossa sociedade atual, a qual nos impõe um olhar que não descarte várias perspectivas e linhas de investigação. Após a experiência proporcionada pela leitura obra, procuraremos ler com um novo "olhar", agora mais amplo, o filme a que assistimos, a obra de arte em geral e o mundo à nossa volta.

3 As relações entre história e memória na construção do filme foram analisadas de maneira mais detida no desenvolvimento da dissertação de mestrado da autora deste artigo. 


\section{REFERÊNCIA BIBLIOGRÁFICA:}

BELLO, Maria do Rosário Lupi. Narrativa literária e narrativa fílmica. 0 caso de Amor de Perdição. Lisboa: Fundação Calouste Gulbenkian - Fundação para a Ciência e a Tecnologia, 2005.

BENJAMIN, Walter. "O narrador" e "A obra de arte na era de sua reprodutibilidade técnica": Magia, técnica, arte e política. 3.ed. São Paulo: Brasiliense, 1994.

BETTELHEIM, Bruno. A psicanálise dos contos de fadas. Trad. Arlene Caetano. Rio de Janeiro: Paz e Terra, 1980.

BRANDÃO, Junito de Souza. Mitologia Grega, vol. III. Petrópolis: Vozes, 2002.

CARVALHAL, Tânia Franco. Literatura comparada. São Paulo: Ática, 2006.

CASSIRER, Ernest. Linguagem e mito. Rio de Janeiro: Perspectiva, 1992.

COELHO, Nelly Novaes. 0 conto de fadas. São Paulo: Ática, 1988.

. A literatura infantil: teoria, análise e didática. São Paulo: Moderna, 2000.

DURAND, Gilbert. A imaginação simbólica. Lisboa: Edições 70, 1995.

EISENSTEIN, Sergei. “Palavra e imagem”: 0 sentido do filme. Rio de Janeiro: Zahar, 1990.

ELIADE, Mircea. Aspectos do Mito. Lisboa: Edições 70, 1963.

GOTLIB, Nádia Battella. Teoria do conto. São Paulo: Ática, 1988.

GUIMARÃES, César. Imagens da memória. Entre o legível e o visível. Belo Horizonte: Editora da UFMG, 1997.

HATOUM, Milton. Relato de um certo Oriente. São Paulo: Companhia das Letras, 2004.

LEITE, Lígia Chiappini Moraes. O foco narrativo. São Paulo: Ática, 2001.

MELLO, Ana Maria Lisboa de. "Mito e literatura”: Revista Ciências das Letras, n 42. Porto Alegre: Fapa, 2007. 
ORWELL, George. Lutando na Espanha: homenagem à Catalunha, recordando a guerra civil espanhola e outros escritos. Trad. Ana Helena Souza. São Paulo: Globo, 2006.

RAMOS, Fernão Pessoa (org.). Teoria contemporânea do cinema, volume II. São Paulo: Senac, 2005.

RIBEIRO, Joana Marques. O percurso do olhar pelo labirinto: os desafios do leitor contemporâneo [dissertação]. São Paulo: “Faculdade de Filosofia, Letras e Ciências Humanas, Universidade de São Paulo", 2011.

SÁNCHEZ-BIOSCA, Vicente. Cine y Guerra Civil Española. Del mito a la memória. Espanha: Alianza, 2006.

SOUSA, Sérgio. Relações intersemióticas entre o cinema e a literatura. A adaptação cinematográfica e a recepção literária no cinema. Braga: Universidade do Minho, 2001.

XAVIER, Ismail (org.). A experiência do cinema. Rio de Janeiro: Graal, 1983.

. “Cinema: revelação e engano”. In: NOVAES, Adauto et al. O olhar. São Paulo: Companhia das Letras, 1988, p.367-383. . O olhar e a cena. São Paulo: Cosac \&Naify, 2003.

\section{FILMOGRAFIA:}

TORO, Guillermo Del. O Labirinto do Fauno (El Laberinto del Fauno). ESP/MEX/EUA: Estúdios Picasso, Tequila Gang e Esperanto Filmoj, 2006. DVD (118 min). 